\title{
PROOF
}

\section{6 \\ Size and Evolution of the Risk Capital Industry}

\author{
Alessandro G. Grasso
}

\section{Introduction}

Operation in the risk capital industry is a very complex undertaking. This complexity derives both from the different main objectives which may be pursued through investments of this kind and the wide variety of organisational/institutional forms involved. Further uncertainty arises from the lack of a standardised definition; this is a hindrance to the publication of data in forms allowing fully reliable comparisons to be made. Nonetheless, this chapter intends to provide a quantitative picture of the private equity and venture capital industry, highlighting the most recent developments in the sector and outlining the main differences still affecting some of the main countries in the European area.

Our survey starts from a comparison between the US and Europe, the two macro areas of reference in which this industry is most highly developed, before moving on to examine in depth the trends in the main European countries: the UK, France, Germany, Sweden, Italy, Spain and the Netherlands, chosen because they accounted for 95 per cent of the total investments in private equity in Europe during 2006.

\section{The drivers of evolution}

According to data supplied by the EVCA (2007a), at year-end 2006, private equity operators world-wide were managing funds of an amazing $\$ 1.3$ trillion, almost 100 times more than 15 years ago. This growth rate and the increasing attention focused on the sector by the academic world, policy-makers and, more recently, the media, may lead us to forget that private equity is in fact a very recent phenomenon. 
This growth in the funds raised and capital invested has been accompanied by a growth in quality terms, involving both the types of operators and the operations carried out, as the industry continues to extend its geographical and operating boundaries.

Generally, the growth drivers of this sector of the financial industry can be studied from both the demand and the supply sides. From the demand side, faced with the gradual reduction of the role of banks, which has occurred in many economies, and especially in Europe, enterprises have been searching for the right amounts of the appropriate types of capital to support and grow their business ideas, especially in the most innovative sectors. In addition, the presence of specialist equity investment firms, viewed as a positive sign by traditional lenders, has often been useful in providing more favourable conditions for access to credit. Simultaneously, for the first time in history the delicate generational handover has occurred in a large number of enterprises concurrently, creating an opening for professionals specialising in the management of this crucial transition.

On the supply side, investors have been looking for new investment opportunities enabling them to increase the return on their portfolios. As we shall discuss in detail in chapter 7 , the growth of the financial markets and the creation of new markets and specific segments focusing on firms with high growth potential has expanded the range of possible disinvestment strategies, making it easier for the risk capital investment sector to achieve large capital gains. The rising number of market operators of this kind and the ongoing consolidation of their performances has attracted ever-increasing attention from investors. Paradoxically, this high degree of attention may become the main cause of a future deceleration in this sector, because 'the financial performance of the industry ultimately drives its success' but 'when there is too much money chasing too few good deals, those good deals tend to be bid up in price early on, making it difficult for venture capital general partners to reward their investors with suitable returns' (EVCA, 2007a, p. 22).

Although investment in risk capital has historical origins (the operations undertaken by British merchants in the fifteenth century, or the later role of the India companies in the development of international trade are only the most obvious examples), there is general agreement that the real venture capital and private equity market was born in the US with the pioneering activities undertaken from the 1940s by L. Rockefeller and J. Whitney. At that time, the investment process was almost entirely in the hands of families and private investors who used their own resources, since the practice of raising funds from the public and 
institutional investors had not yet been established (Wilson, 1985). The foundation of the American Research and Development Corporation (ARD) in 1946 was the first major step towards the creation of a financial sector operating on the principles of private equity and venture capital. Specifically, the ARD pioneered the practical experimentation of a number of features of venture capital as we understand it today: it raised funds from the public, invested in high-tech enterprises and provided managerial assistance to firms.

In practice, such activities were limited in scale until 1958, when the US Congress passed the Small Business Investment Act. Together with other measures discussed in detail in chapter 8, this Act authorised the establishment of Small Business Investment Companies (SBICs), private firms which could access financing and collateral to allow them to invest in unlisted small enterprises. Subsequently, reductions in the rate of taxation of capital gains, and especially the repeal in 1979 of the Employee Retirement Income Security Act (ERISA), which forbade pension funds from investing in venture capital or other high-risk asset classes, encouraged strong growth in the flows of funds towards this type of intermediary. With the passage of time and the coming to maturity of the sector, this growth has increased dramatically, in spite of periods of contraction of economic growth and alternating trends in share prices on the official markets.

Turning our attention to Europe, the birth and development of the private equity market can be traced to the UK. It is a widely believed that, apart from sporadic individual events such as the establishment in 1945 of the Industrial and Commercial Finance Corporation (ICFC), known today as 3i - Investors in Industry - one of Europe's biggest institutional investors, until the 1980s the European private equity sector was about a quarter of a century behind its US counterpart in terms of its development (Cary, 1999). The birth of a real European venture capital and private equity industry can be traced to the 1980s, with a number of formal measures, (Gervasoni and Sattin, 2000). Among them, in December 1980 the Council of Europe, recognising the strategic importance of the development of new technologies and the difficulties European small entrepreneurs were having in accessing the risk capital market, decided to create its Venture Capital Liaison Office, with the task of establishing contacts between potential investors and investees. Subsequently, in August 1983, the EU was involved in the formation of the European Private Equity and Venture Capital Association (EVCA). Partly thanks to these organisations, since the 1990s the European market has enjoyed rapid 


\section{PROOF}

Size and Evolution of the Risk Capital Industry 89

growth, even though, as we shall see, there have been periods of sharp deceleration.

Elsewhere, with the exceptions of Canada, Israel and Japan, the risk capital investment sector has developed with a time-lag of several decades, although the gap has been narrowing. Wright et al. (2005) provide an interesting survey of the research which has attempted to explain the drivers underlying the growth of private equity and venture capital in different geographical contexts.

Black and Gilson (1998) show that the larger number of operators involved in this sector in economic systems which have more highly developed stock markets may be explained by the greater ease with which exit strategies can be created. Jeng and Wells (2000) and Megginson (2004), on the other hand, support the reasoning of Black and Gilson, but consider that the growth of market capitalisation is not vital for the appearance of venture capital and private equity operators; in their view, policy measures can have more impact by modifying the regulatory framework. Jeng and Wells also make an important distinction between factors that encourage the spread of early stage rather than later stage venture capital, noting that the process of stock market listing (IPOs) is only crucial for later stage investment. In this area, Bottazzi and Da Rin (2002) reveal that the presence of venture capital intermediaries does not necessarily lead to an increase in the number of stock market flotations. Nye and Wasserman (1999) studied the growth of the venture capital sector in India and Israel, and concluded that different degrees of political interest, quality of infrastructures and cultural factors may create differences in the development of venture capital markets. Kenney et al. (2002) reached similar conclusions from their examination of the Asian markets. They also suggest that the risk capital investment industry may generate different types of operators, with specific objectives, depending on the economic context.

The importance of risk capital investment at the international level during the last few years is due to the role of a variety of factors. On the one hand, a large number of developing countries are pursuing radical reforms in an attempt to attract the attention of investors seeking new business areas as the number of investment opportunities in the traditional market contracts (Gompers and Lerner, 1998); on the other, opportunities are arising for transnational investment (Aylward, 1998) by foreign operators in economic contexts where there is little domestic capital available, helping to stimulate the financial and economic growth of these contexts (Maula and Mäkelä, 2003). Recently, the sovereign funds have also been turning their attention to this area, especially the 


\section{PROOF}

90 Alessandro G. Grasso

Chinese government, which purchased a 10 per cent stake in one of the world's largest private equity fund management firms, Blackstone Group Investment, at the time of its stock market flotation.

Alongside the increase in the amount of capital raised, the regulators have also been showing increasing interest in the risk capital investment sector. For example, in 2006, for the first time, the Financial Services Authority (2006) turned its attention to the private equity market by surveying its recent developments: the growing level of institutionalisation of the investor base, a strong role for the managers of the investee companies, development of a secondary market in the sector, standardisation of the private equity model, more competition and an increase in the number of corporate delistings.

\section{Europe vs. the US: a closer look}

Although the trend in Europe and the US, the two most highly developed geographical areas (Figure 6.1), has been one of growth overall, there have been times when the market has contracted. The favourable trend in the financial markets, which have thus offered a possible way out for this type of investment, has been one influence on operators' investment decisions.

As Figure 6.1 shows, historically the amount of funds raised for private equity operations has been higher in the US than the European market, although the gap between the two is gradually closing. Until 2000 the US market grew rapidly, peaking at almost 2 per cent of GDP. This value, never subsequently equalled, was followed by a drastic decline, triggered by the bursting of the dot.com bubble on the stock markets, which in 2002 brought the situation in the US in line with that in Europe. The US market then started to grow again rapidly, reflecting the sector's flexibility and maturity. In Europe, at the same time, after two years of relative tranquillity, the annual commitment as a proportion of GDP increased drastically, almost making up the historic deficit compared to the US.

This outstanding performance of the European market can be traced to the many large industrial groups' need for restructuring and privatisation, the problems related to the generational transition as the founders of many firms bowed out and the opportunities for the launch of new, high-tech business ventures. These conditions provided a growing number of opportunities for investment in start-up, expansion, replacement and buy-out operations, while simultaneously attracting huge amounts of capital, partly from foreign investors, especially from the US, in search of more attractive investments. It is worth mentioning that 28.8 per cent 


\section{PROOF}

Size and Evolution of the Risk Capital Industry 91

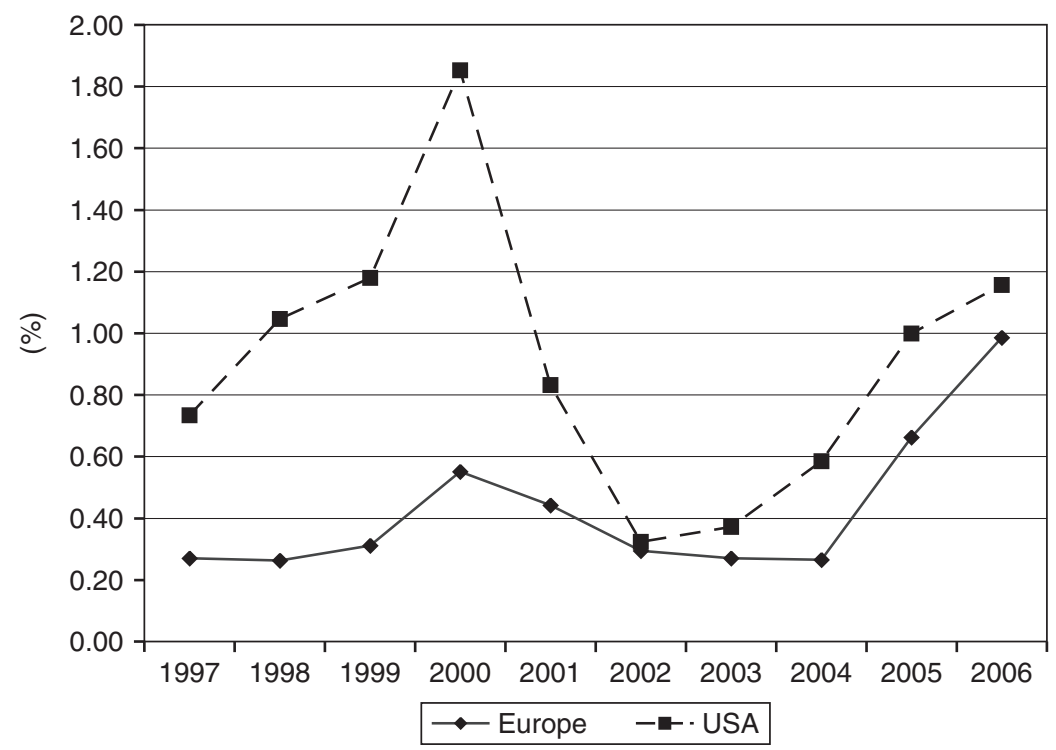

Figure 6.1 Europe vs. US - funds raised on GDP (\%)

Source: elaborations on EVCA (2007a) and NVCA (2007). For GDP: Eurostat and US Bureau of Economis Analysis.

of the funds raised on the European market in 2006 came from US investors (EVCA, 2007a).

Considering the expected allocation of the funds raised in 2006, both the US and the European markets confirm the trend noted since 2001, in which buy-out operations continue to be the main investment strategy (Figure 6.2). In Europe, the amount of capital committed for venture capital investments surged to $€ 17.5$ billion, but in spite of this, three-quarters of the funds raised were utilised for buy-out operations. On the US market, the funds raised for venture capital operations amounted to \$29.9 billion, and here again the attractiveness of buy-outs was confirmed, accounting for 80.4 per cent of the capital committed.

Focusing on venture capital operations alone, and considering the 2002-6 trend, there is a clear prevalence of expansion operations on both the US and the European markets (Figure 6.3). Bearing in mind the definitions supplied by the two largest associations in the industry, different segmentations emerge in the venture capital sector as a whole; to allow more immediate comparison, we subdivided venture capital into two discrete areas. To avoid terminological confusion, the two areas are called 


\section{PROOF}

92 Alessandro G. Grasso

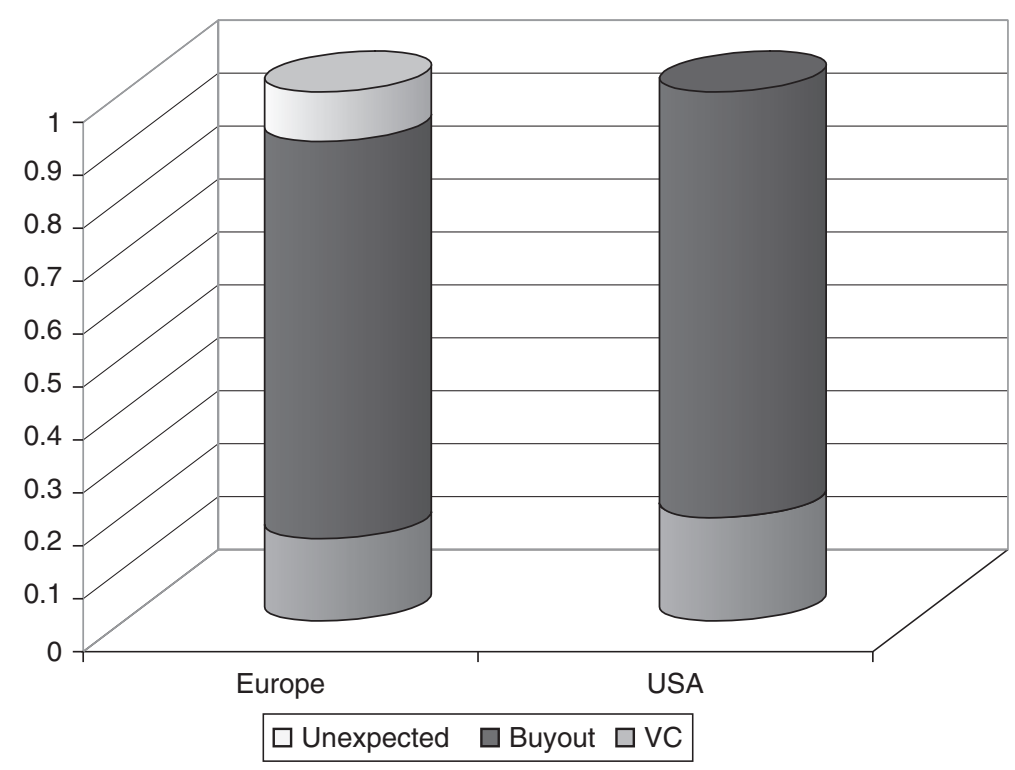

Figure 6.2 Europe vs. US - expected allocation of funds raised in 2006 (\%) Source: based on EVCA (2007a) and NVCA (2007).

Stage A and Stage B. Stage A includes all investments made in firms in the initial, seed and start-up stages of their life cycles, and Stage B, all operations relating to the subsequent expansion stage. ${ }^{1}$ Considering Stage B alone, for the US market the average threshold is around 80.4 per cent for the period. The European market also shows a clear prevalence of Stage B operations, although for 2006 an increase in the amount invested in seed and start-up financing operations can be noted. Seed operations in particular grew considerably, with an increase from €97 million in 2005 to $€ 1.7$ billion in 2006, while start-up investments in Europe doubled, rising from $€ 2.3$ billion in 2005 to $€ 5.7$ billion in 2006 .

\section{A picture of the European private equity industry}

Moving on to a more detailed analysis of the European market, we looked in depth at the seven most important countries (United Kingdom, France, Sweden, Germany, Spain, the Netherlands and Italy), which account for about 95 per cent of total European investments in private equity in 2006 (Table 6.1). $^{2}$ 


\section{PROOF}

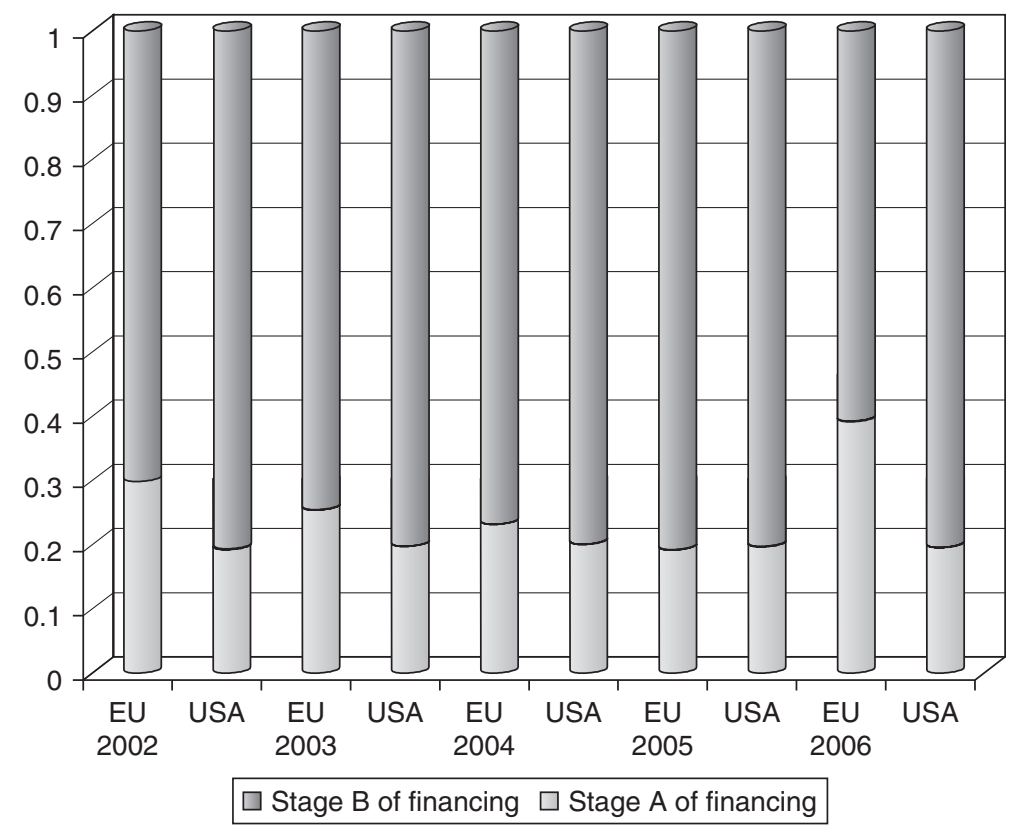

Figure 6.3 Europe vs. US - investment composition by stage, 2002-6 Source: elaborations on EVCA (2007a) and NVCA (2007).

Table 6.1 The private equity market in 2006

\begin{tabular}{lrccc}
\hline & $\begin{array}{l}\text { Funds raised } \\
(\mathbf{\in m})\end{array}$ & $\begin{array}{l}\text { Amount } \\
\text { invested } \\
(\mathbf{\epsilon m})\end{array}$ & $\begin{array}{l}\text { Funds raised } \\
\text { on GDP (\%) }\end{array}$ & $\begin{array}{l}\text { Amount } \\
\text { invested } \\
\text { in GDP (\%) }\end{array}$ \\
\hline United Kingdom & 74,993 & 40,897 & 3.92 & 2.14 \\
France & 10,617 & 10,100 & 0.59 & 0.56 \\
Sweden & 9,397 & 4,259 & 3.00 & 1.36 \\
Germany & 2,819 & 3,518 & 0.12 & 0.15 \\
Italy & 2,275 & 3,415 & 0.15 & 0.23 \\
Spain & 2,884 & 2,815 & 0.29 & 0.29 \\
Netherlands & 2,609 & 2,393 & 0.49 & 0.45 \\
Total & 105,594 & 67,397 & 1.13 & 0.72 \\
Total (excl. UK) & 30,601 & 26,500 & 0.41 & 0.36 \\
\hline
\end{tabular}

Source: elaborations on EVCA (2007a). 
Some interesting data emerge from the comparison between volumes invested and funds raised, evaluated in absolute terms and as a fraction of GDP (Table 6.1).

The figures for commitments and investments in relation to GDP highlight the difference between the UK and continental Europe. The UK historically is the European country which has achieved and consolidated the highest degree of development in its risk capital market. Its large lead in this area is explained by cultural reasons and by the fact that the sector has been established for longer in the UK than elsewhere in Europe. This aspect has significant repercussions on strategic factors, such as the amount of experience built up by operators and how well informed investors tend to be with regard to risk capital investments. The UK's role clearly emerges if the average figure for the total sample of the seven countries is compared with the figure excluding the UK. Sweden is also well ahead of the other European states, as the sector is growing strongly in this country.

In addition, Table 6.1 enables us to point out the discrepancy between the amount of funds raised and invested. This difference allows us to identify a clear time lag between fund-raising and investment opportunities probably underlying the market shortage of operations that meet the risk/return profiles required by operators.

In terms of fund-raising strategies, considering only the funds raised in 2006 and not including the capital deriving from realised capital gains, the major role played by financial institutions as investors is clear (Table 6.2). The most important category of investor may vary depending on context; in Italy, the banking system has the lion's share, since 70.7 per cent of private equity firms are captives, while in the UK the key role is played by the pension funds, which supply capital to independent operators. Funds of funds are found in all the contexts considered, while academic institutions, major players in the UK, have only recently begun to consider this investment area in the rest of Europe. Bearing in mind the considerable influence of the UK market on the total figure, the European statistic indicates that government agencies play an important role, in particular in Germany and Spain.

Turning our attention to the ability of the economic context to attract capital, reinforcing the statement made initially, 2006 confirms Europe's importance as an investment area (Table 6.3). When the situation is examined at the country-by-country level, two scenarios emerge. On the one hand, we have Sweden and the UK, where a major proportion of the capital committed is used for investment abroad; on the other, in the other sample countries more than two-thirds of the funds raised 


\section{PROOF}

95

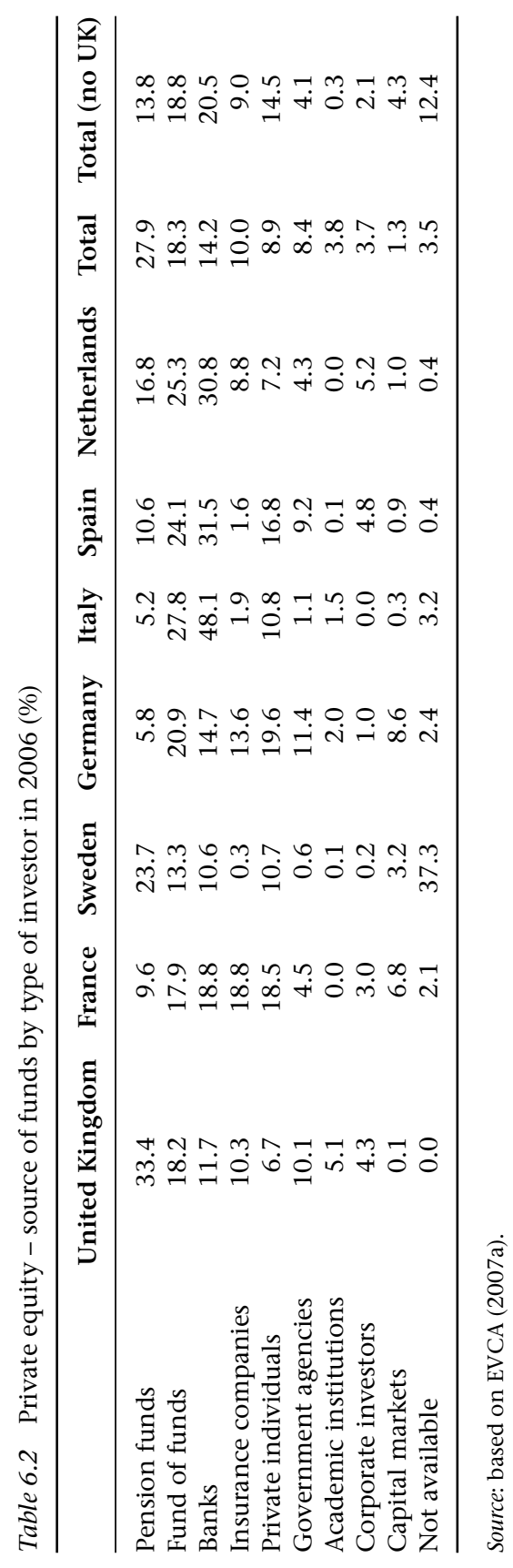




\section{PROOF}

96 Alessandro G. Grasso

Table 6.3 Private equity - geographical distribution of investments in 2006

\begin{tabular}{lrrrrr}
\hline & $\begin{array}{l}\text { Domestic } \\
(\mathbf{( m )})\end{array}$ & $\begin{array}{l}\text { Domestic } \\
(\mathbf{\%})\end{array}$ & $\begin{array}{l}\text { Other } \\
\text { countries } \\
(\mathbf{( m )})\end{array}$ & $\begin{array}{l}\text { Other } \\
\text { countries } \\
(\mathbf{\%})\end{array}$ & $\begin{array}{l}\text { Total } \\
\text { investment } \\
(\mathbf{€ m})\end{array}$ \\
\hline United Kingdom & 22,248 & 54.4 & 18,649 & 45.6 & 40,897 \\
France & 8,370 & 82.9 & 1,730 & 17.1 & 10,100 \\
Sweden & 2,809 & 66.0 & 1,450 & 34.0 & 4,259 \\
Germany & 3,174 & 90.2 & 344 & 9.8 & 3,518 \\
Italy & 3,373 & 98.8 & 42 & 1.2 & 3,415 \\
Spain & 2,529 & 89.8 & 286 & 10.2 & 2,815 \\
Netherlands & 2,048 & 85.6 & 345 & 14.4 & 2,393 \\
Total & 44,550 & 66.1 & 22,847 & 33.9 & 67,397 \\
Total (excl. UK) & 22,302 & 84.2 & 4,197 & 15.8 & 26,500 \\
\hline
\end{tabular}

Source: based on EVCA (2007a).

Table 6.4 Private equity - initial and follow-on investments in 2006

\begin{tabular}{lccccc}
\hline & $\begin{array}{l}\text { Initial } \\
\text { investment } \\
(\mathbf{( m )})\end{array}$ & $\begin{array}{l}\text { Initial } \\
\text { investment } \\
(\mathbf{\%})\end{array}$ & $\begin{array}{l}\text { Follow-on } \\
\text { investment } \\
(\mathbf{E m})\end{array}$ & $\begin{array}{l}\text { Follow-on } \\
\text { investment } \\
(\%)\end{array}$ & $\begin{array}{l}\text { Total } \\
\text { investment } \\
\text { in year (€m) }\end{array}$ \\
\hline United & 36,334 & 88.8 & 4,564 & 11.2 & 40,898 \\
$\quad$ Kingdom & & & & & \\
France & 8,682 & 86.0 & 1,419 & 14.0 & 10,101 \\
Sweden & 3,561 & 83.6 & 698 & 16.4 & 4,259 \\
Germany & 3,196 & 90.8 & 322 & 9.2 & 3,518 \\
Italy & 1,503 & 44.0 & 1,912 & 56.0 & 3,415 \\
Spain & 2,623 & 93.2 & 192 & 6.8 & 2,815 \\
Netherlands & 1,859 & 77.7 & 534 & 22.3 & 2,393 \\
Total & 57,757 & 85.7 & 9,640 & 14.3 & 67,397 \\
Total & 21,424 & 80.8 & 5,076 & 19.2 & 26,500 \\
(excl. UK) & & & & & \\
\hline
\end{tabular}

Source: based on EVCA (2007a).

are invested within national borders, with a peak for the Italian market, where this figure reaches 99 per cent.

When a distinction is made between initial and follow-on investments (Table 6.4), it can be seen that on average 86 per cent of the investments made are in firms in which the investor did not previously have a holding. This is particularly true in Germany, the UK and Spain, while in 


\section{PROOF}

Size and Evolution of the Risk Capital Industry 97

Italy a surprisingly high proportion of funds are used for follow-on operations, with about 56 per cent of capital allocated for the continuation of operations already underway.

Turning to the subdivision by sector of investment (Table 6.5), according to the EVCA definitions, when the data are split between high-tech and non-high-tech firms, the majority of operations are seen to involve non-high-tech companies. This fits in with various expectations. First, as we shall see, the main type of operation is the buy-out, and at present most of these still tend to involve companies in traditional sectors. Second, it is difficult for statistics to provide confirmation of a progressive shift in investors' attention towards innovation, which is gradually although slowly gaining momentum, at least in some regions of Europe. When the type of investment is considered in relation to GDP, as previously seen in Table 6.1, the figures for both the UK and Sweden differ significantly from the average.

Interesting findings emerge from an observation of the data on the types of operators involved (Table 6.6). The role of the public sector is very small in terms of amount invested and the number of investments made. Only in Spain does the figure invested in 2006 exceed $€ 100$ million. In the other countries in the sample, it is only in Sweden that the capital invested exceeds $€ 50$ million, while in the UK and the Netherlands the EVCA reports no involvement on the part of public operators at all. In the case of Italy, 53 per cent of the early stage investments made in 2006 were by public operators, especially at the regional level (AIFI, 2007). The investment firms established by the regional governments, therefore, seem to be the main source of financing for innovative firms in the seed and start-up stages. It must, however, be pointed out that we are talking about 53 per cent of not very much; the total amount of early stage investments made by public operators in 2006 was just $€ 28$ million. When we cross the figures for the number of operations and the amount invested, Germany is the only country in which the average amount invested by public and private operators is the same, at $€ 4$ million. In the other countries considered, even when public investors are involved, the small size of the operations they undertake clearly emerges. This is in line with the findings of the literature on the public role in supporting the initial stages of a firm's life cycle (see chapter 8).

With regard to the breakdown of investments by type, in 2006, for the aggregate of the European countries considered here, there was an overwhelming preference for buy-out operations of the kind already described; operations of this kind absorbed about 69 per cent of the $€ 67.3$ billion invested (Table 6.7). 
PROOF

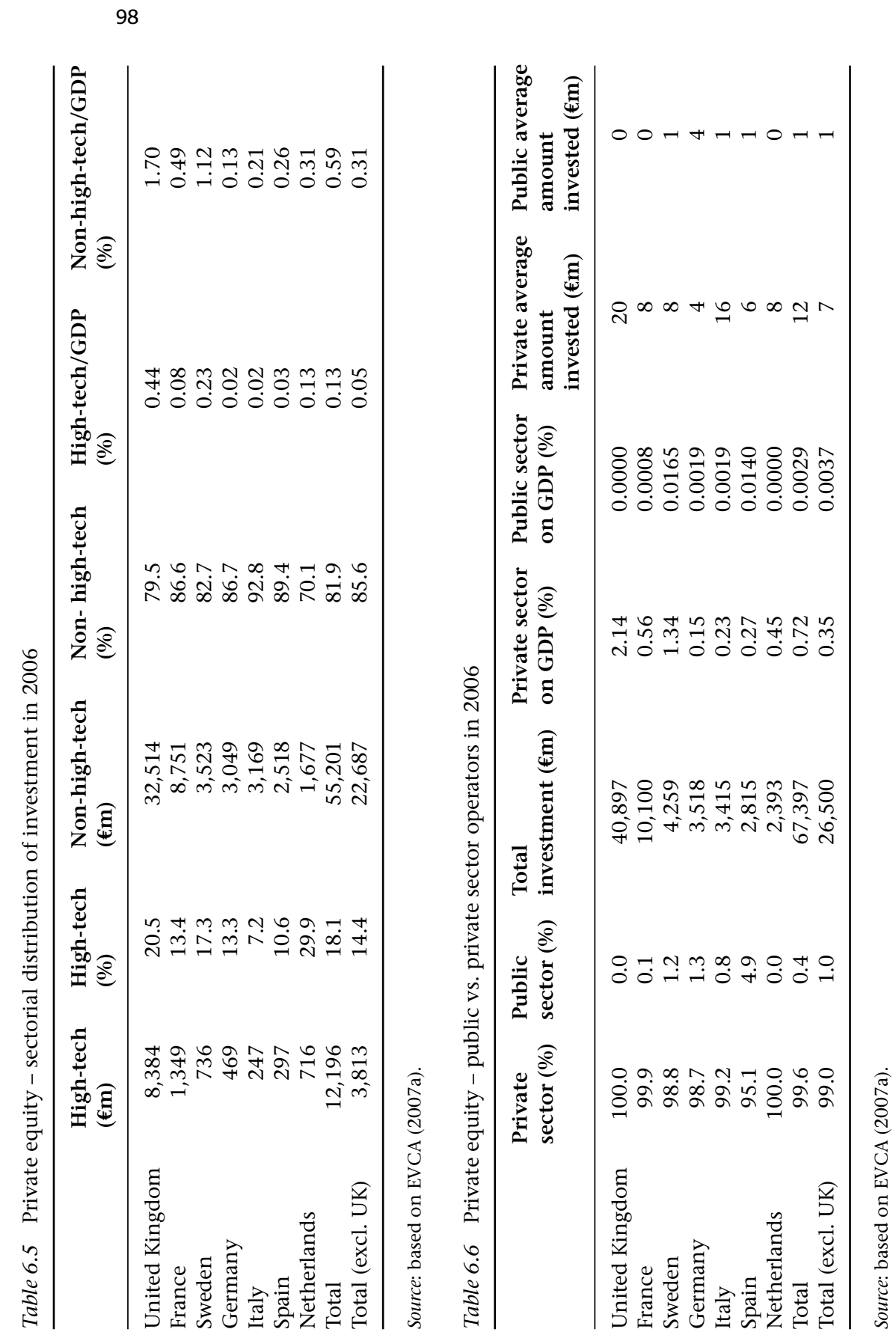




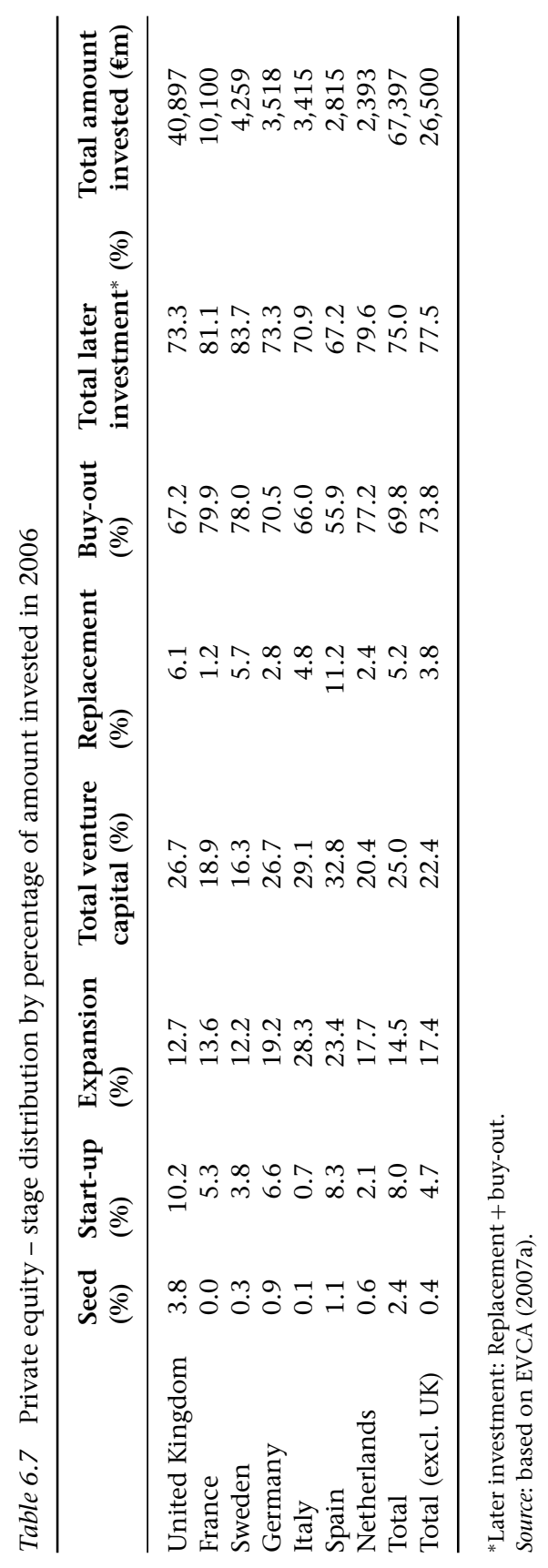


Table 6.8 Private equity - stage distribution by number of investments in 2006

\begin{tabular}{lrrrcrr}
\hline & Seed & Start-up & Expansion & Replacement & Buy-out & Total \\
\hline United Kingdom & 136 & 567 & 734 & 110 & 491 & 2,038 \\
France & 0 & 335 & 611 & 66 & 362 & 1,374 \\
Sweden & 43 & 198 & 194 & 19 & 92 & 546 \\
Germany & 68 & 269 & 525 & 16 & 91 & 969 \\
Italy & 13 & 44 & 94 & 25 & 67 & 243 \\
Spain & 110 & 137 & 316 & 19 & 51 & 633 \\
Netherlands & 7 & 58 & 148 & 14 & 85 & 312 \\
Total & 377 & 1,608 & 2,622 & 269 & 1,239 & 6,115 \\
Total (excl. UK) & 241 & 1,041 & 1,888 & 159 & 748 & 4,077 \\
\hline
\end{tabular}

Source: based on EVCA (2007a).

While a significant proportion of investments were in expansion financing operations (14.5 per cent), in 2006 other types of venture capital operations accounted for extremely small quotas, with an average of 8 per cent at the aggregate level for start-up financing and 2.4 per cent for seed financing. When the influence of the UK is excluded, the weight of investments in the early stages is even lower.

Apart from the UK, the countries among those considered which have the largest proportion of venture capital investments are Germany, Spain and Italy. When these venture capital investments are subdivided into the three main segments, the differences among the situations in these countries clearly emerge. In Italy there is a sharp prevalence of expansion operations, while in Spain and Germany investments are more evenly distributed over the first two stages.

When we consider the number of investments made by type (Table 6.8), as it would be reasonable to expect, there are fewer buy-out than expansion and start-up financing operations, since these investments require more capital. It is worth highlighting the situation in Spain and Germany, where more than 10 per cent of operations provide seed financing, confirming the comments made on the growth of the private equity segment specialising in new business ventures in these two countries. The situation in France is partly different, with no seed operations and about 30 per cent of all operations involving start-up financing.

Confirming the points just made, Table 6.9 provides the figures for the average investment size for each type of investment. The distribution of investments is the same for all the countries considered. As the firm proceeds through its life cycle, the amount invested increases. This is in line 
Table 6.9 Private equity - average amount invested per stage in 2006

\begin{tabular}{|c|c|c|c|c|c|c|}
\hline & $\begin{array}{l}\text { Seed } \\
(€ m)\end{array}$ & $\begin{array}{l}\text { Start-up } \\
(€ \mathbf{E})\end{array}$ & $\begin{array}{l}\text { Expansion } \\
(€ \mathrm{~m})\end{array}$ & $\begin{array}{l}\text { Replacement } \\
(€ \mathrm{~m})\end{array}$ & $\begin{array}{l}\text { Buy-out } \\
\text { (€m) }\end{array}$ & $\begin{array}{l}\text { Total } \\
\text { average } \\
\text { (€m) }\end{array}$ \\
\hline United Kingdom & 11.43 & 7.36 & 7.08 & 22.68 & 55.97 & 20.07 \\
\hline France & 0.00 & 1.60 & 2.25 & 1.78 & 22.31 & 7.35 \\
\hline Sweden & 0.33 & 0.83 & 2.67 & 12.74 & 36.10 & 7.80 \\
\hline Germany & 0.46 & 0.87 & 1.29 & 6.11 & 27.25 & 3.63 \\
\hline Italy & 0.30 & 0.56 & 10.27 & 6.61 & 33.66 & 14.05 \\
\hline Spain & 0.29 & 1.71 & 2.08 & 16.64 & 30.88 & 4.45 \\
\hline Netherlands & 2.18 & 0.85 & 2.86 & 4.11 & 21.74 & 7.67 \\
\hline Total & 4.38 & 3.37 & 3.37 & 12.98 & 37.96 & 11.02 \\
\hline Total (excl. UK) & 0.40 & 1.19 & 1.19 & 6.26 & 26.14 & 6.50 \\
\hline
\end{tabular}

Source: based on EVCA (2007a).

with the fairly conservative risk profile typical of the European private equity industry down to the present day and with the findings in the literature, which reports that the size of operations increases as the target company matures. It is thus logical that buy-out operations absorb the most capital. With reference to venture capital, it is worth noting that in the UK and the Netherlands, the average amount invested in the seed capital stage is greater than that for start-up operations. Another figure of interest, related to the seed stage, is that in the UK $€ 1.55$ billion was invested in 136 operations, with $€ 11.43$ million invested on average.

Finally, turning our attention to the disinvestment channels used in 2006, it emerges that within the sample as a whole the most widely used channel is trade sale, followed by sale to financial institutions and divestment by repayment of preference share/loans (Figure 6.4). ${ }^{3}$ Disinvestment by means of stock exchange listing was the option pursued in several cases, and the volumes involved in this channel were larger than in 2005 (EVCA, 2007a). Write-offs account for less than 5 per cent of disinvestments. The disinvestment channel depends not only on the operator's preferences, but also on the current macroeconomic conditions.

When our analysis is extended to consider country-specific factors, we find that in Italy the financial institutions play a leading role; this is to be expected for a market where investments are in more mature firms, which attract the attention of financial operators. In the UK, on the other 


\section{PROOF}

102

Alessandro G. Grasso

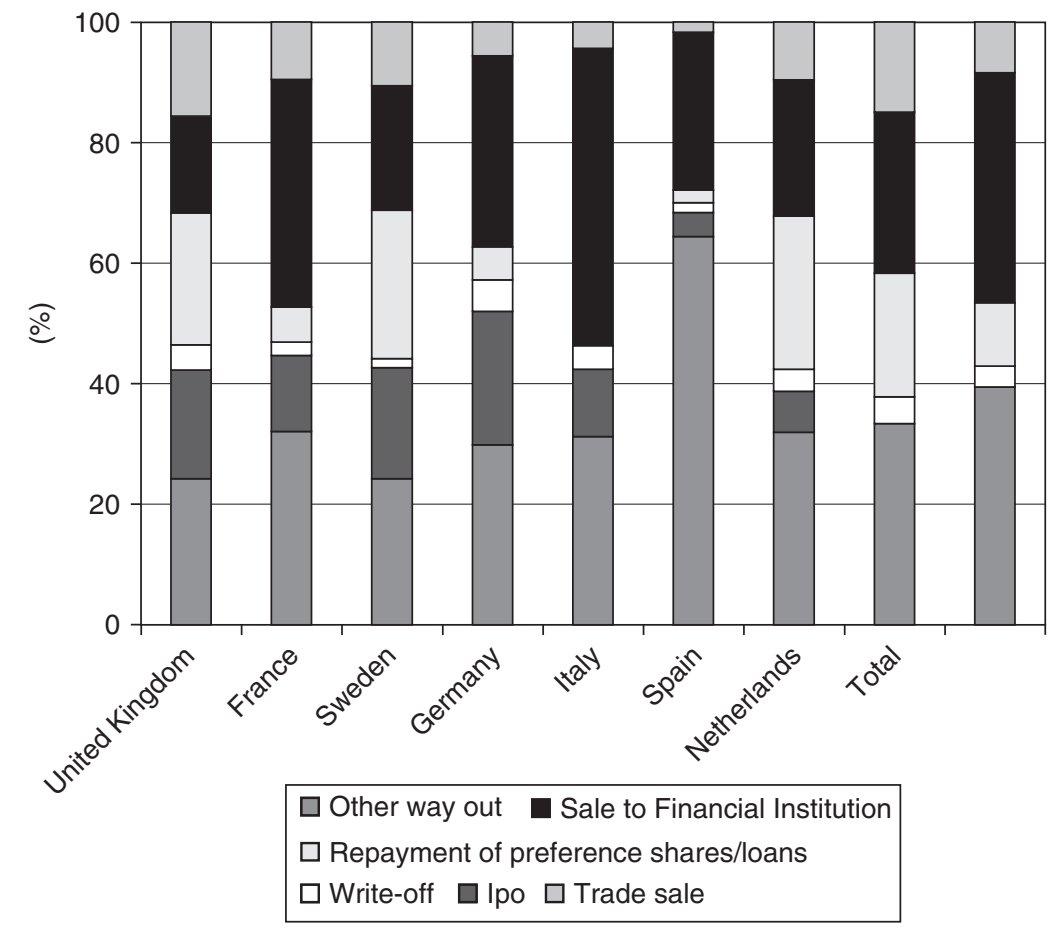

Figure 6.4 Private equity - way-out mechanisms distribution in 2006 (\%) Source: based on EVCA (2007a).

hand, most disinvestment is by means of the listing process, reflecting the higher level of efficiency achieved by this country's stock markets.

\section{Risk capital investment as an asset class}

The record of the funds raised in Europe and the US reflects investors' faith in the private equity industry's ability to prosper in the mediumto-long term and generate worthwhile returns.

It should be remembered that the yield of the market for institutional investment in risk capital over any given period of time is affected by a number of factors, in particular:

- the size of the market, the number of operators it involves and its consequent level of competitiveness, which affects the prices of the target firms; 
Table 6.10 Europe vs. US - performance of private equity investments (\%)

\begin{tabular}{lcccc}
\hline & One year & Three years & Five years & Ten years \\
\hline Total venture capital Europe & 17.2 & 5.0 & -2.0 & 4.1 \\
Total venture capital US & 7.0 & 9.1 & -1.2 & 20.5 \\
Total buy-out Europe & 29.6 & 15.3 & 8.3 & 14.3 \\
Total buy-out US & 21.6 & 15.6 & 9.1 & 8.8 \\
Total European private equity & 36.0 & 13.0 & 5.0 & 11.0 \\
Total US private equity & 16.5 & 13.0 & 6.0 & 11.0 \\
\hline
\end{tabular}

Source: based on EVCA (2007a) and NVCA (2007).

- operators' success in creating value in the venture-backed firm, which depends on their level of professional expertise and on the characteristics of the target firm itself;

- the efficiency of the disinvestment channels and their economic performance; this is key to the availability of a range of good disinvestment opportunities and the opportunity to exploit positive trends in the market and company evaluations to obtain higher prices.

Table 6.10 shows the returns achieved by private equity operators, divided between venture capitalists and buy-outs, for the US and Europe. It is clear that the trends in performance tend to be the same in both the US and the European markets. In the long term, the performance of private equity investments is good, yielding about 11 per cent per annum, net of all the commissions paid to the operators. This positive return is maintained throughout the period considered, and in 2006 the European market showed a return of 36 per cent over one year, outperforming the US market, which achieved 16.5 per cent. This justifies the figure on European fund-raising, which reflects the high level of interest of US operators in this market.

With regard to the segmentation of performance by type of operation, according to classical financial theory, with application of the risk/return principle, seed and start-up operations should be more profitable in the light of their higher risk profile. However, the real figure may be sharply different since, as we have seen, in spite of operators' efforts to limit the degree of uncertainty concerning future events, the final return on the operation is strongly dependent on contingent factors.

If we look at the European market in the short and long term, it is clear that buy-out operations offer the best returns for investments. Over a tenyear time horizon, buy-outs generated returns of 14.3 per cent, while the 
average return on venture capital was 4.1 per cent. In the short term, the yield provided by venture capital investments is decidedly better, at 17.2 per cent, but it is still below the return provided by buy-out operations at 29.6 per cent.

The situation of the US market is different with regard to mediumto-long-term returns. As classical theory indicates, in this market the net return achieved by venture capital investors over a ten-year period is higher, at 20.5 per cent per annum, than the return on buy-out operations, which is 8.8 per cent. However, if the time scale is shortened, the trend becomes the same as in the European markets. In 2006, buy-out operations generated returns of 21.6 per cent, while the yield on venture capital operations was stationary at an average of 7 per cent.

Another factor that can effect the return on investment in the European and US markets is the average amount invested in venture capital operations. This is particularly evident when targeting technology firms: $€ 900,000$ in Europe, $€ 6.1$ million in the US. This figure is even more striking when referred to seed and start-up financing operations: for this kind of firm, in Europe it is $€ 500,000$ and $€ 800,000$ respectively, while in the US it rises to $€ 1.8$ million and $€ 4$ million (EVCA, 2007a). The differences in terms of average amount invested can have various effects, including limiting the potential growth of the investee enterprises, and thus limiting the return on the investment (European Commission, 2006a).

From the asset management point of view, investments in risk capital are classified within the alternative investments category. Among others, this category includes hedge funds, real estate funds and private equity funds. It is not uncommon for private equity and hedge fund operators to be placed on the same plane. Without going into detail, we can state that hedge funds, like private equity firms, are often active investors in the risk capital of the enterprises in which they hold shares. On the one hand, this active involvement distinguishes them from traditional institutional investors, while on the other, it is due to this role in corporate governance that the distinction between hedge funds and private equity funds may be fuzzy (European Commission, 2006c). The active involvement may assume various forms: from putting public pressure on the management to obtain changes in business strategy, to membership of the board of directors and the imposition of new managers. One indirect effect of this active participation is that it creates the need for regulation of the financial markets to control it (European Central Bank, 2007). However, unlike private equity investors, hedge funds often have an excessive orientation towards short-term objectives. This may also be 
true of private equity in some cases, but its investments normally have medium-to-long-term time horizons.

Once the main distinction between the most important segments of the alternative investment category has been made clear, viewing the risk capital investment market as an asset class highlights several key features:

- It is an extremely heterogeneous market, with a wide difference in returns between the various operators.

- Performances cannot be assessed immediately. The investment portfolio consists of financial assets which often cannot be valued with any certainty since they are not traded on the financial markets. Moreover, the earnings of private equity investors, and especially venture capitalists, follow a trend known as the J-curve phenomenon: during the initial years of operations returns are negative, since the annual operating costs have to be met and no disinvestments are made. This phenomenon means that the early loss of value of an investment in a venture capital fund does not necessarily give an indication of the profitability of the investment over time. For the same reason, comparing the profitability of a two-year-old fund to one that has been operating for, say, seven or eight years would not be meaningful (Dantas and Raade, 2006).

- The lack of information transparency, the varying opinions as to what actually constitute private equity and venture capital operations, and the high level of discontinuity in the results depending on the time horizon considered all render comparisons between statistical studies problematic.

As seen, we are thus faced with an economic sector in which no immediate, definitive conclusions can be drawn.

There is no denying the amount of interest in this sector, reflected by the high flows of capital into it on several occasions, attracted by the high returns achieved in a many cases. In the US buy-out market, for example, three periods can be identified: between 1986 and 1998 the private equity industry raised about $\$ 16-18$ billion a year; the subsequent decline was followed by a second period from 1995 to 2000, during which the inflow of capital again accelerated, reaching a new record of $\$ 80$ billion in 2000; finally, after another decline between 2001 and 2003, investors' interest returned, with $\$ 150$ billion collected in 2006 (Chew, 2007).

In spite of the considerable inflow of capital, various studies have revealed uncertainty concerning the sector's profitability; Conroy and 


\section{PROOF}

Harris (2007) state that the average net rate of return for investors in private equity operations has not been as attractive as many people suppose. The risks are often underestimated and returns overestimated, largely due to the methods used to estimate and report the value of investments.

Moreover, the situation varies depending on the geographical context. On average, the return on venture capital investments in Europe is very low. According to the data analysed by Dantas and Raade (2006) as of 2003 the average annual return on investments made at five and ten years was +2.3 per cent and +8.3 per cent. The performance of investments in early stage firms was particularly disappointing, with an annual return after five years of -1.8 per cent and after ten years of +1.3 per cent. In the case of expansion investments, the annual returns rise to +4.6 per cent and +10.7 per cent respectively in the same time frame. These data clearly reveal uncertainty with regard to the ability of venture capital investments to compete with alternative assets, such as hedge funds or real estate funds, on the basis of the return in proportion to the risk undertaken. In the US market, we find a venture capital industry with significantly higher annual returns: +22.8 per cent and +25.4 per cent respectively, on the same five- and ten-year time horizons. In the case of early stage investments, returns are even higher, with +54.9 per cent and +37 per cent, while the returns on expansion investments are less outstanding, although still significantly higher than those achieved in Europe -+19.4 per cent and +20.4 per cent.

One of the basic causes of this disparity is the fragmentation of the European market, which restricts its efficiency. Since the opportunities for cross-border investments are still very limited, many firms are not sufficiently specialised and do not develop the expertise required to make investments in specific sectors, especially those with a high degree of innovation. As a result, the European market is less efficient and its returns are unattractive compared to those available in the US (European Commission, 2006c).

As already mentioned, profitability levels in the risk capital investment industry vary widely. Kaplan and Schoar (2005) compared the median return on investments made and liquidated between 1980 and 2001, and obtained figures of +13 per cent for buy-out and +11 per cent for venture capital operations, with average returns of +18 per cent and +17 per cent. The comparison reveals that while some funds have achieved very high returns, the earnings provided by others have been extremely low.

There is also the problem of defining the risk/return profile of risk capital investments due to a number of factors, including the measurement 
of returns, the fact that these are not liquid investments and the representativeness of prices.

It is difficult to calculate the return on investments during the investment instruments' life, because the prices of operations not yet concluded are recorded at the purchase cost, or not reported at all. In addition, these are investments in instruments such as limited partnerships or closed-end funds, which are not liquid because there is no obligation to list them, and the assets in which the fund invests are often themselves not listed, and so any stated prices are not truly representative. Conroy and Harrys (2007) state that a significant part of the value assigned to a fund arises from the 'remaining value to paid-in', estimated by the general partner, which at the end of 2004, in the European market, was 40 per cent of the value expected by the investors.

Cumming and Walz (2004) show that the differences in return among all the types of risk capital investments derive to a large extent from the corporate governance mechanisms adopted; in the contexts with the highest degree of legality, performances are better (Cumming et al., 2007).

\section{Conclusions}

Differences remain on the quantitative level between the US and European markets with regard to the amounts of funds raised, with the US market leading the way, although the gap is gradually narrowing. However, from the qualitative point of view, the industry's development seems to be powered by quite similar drivers on both sides of the Atlantic, with a prevalence of buy-out operations and the concentration of venture capital operations in the expansion financing segment.

This similarity between the two areas can be explained if we consider the primary role played by the British private equity market in Europe. Like their US counterparts, British operators give particular importance to objectives linked to economic efficiency, achieved by exploiting the economies of scale generated by the huge amounts of assets managed, and they therefore concentrate on investment operations of a higher average size. The situations in the other European countries vary.

Apart from the UK, the countries with the largest proportion of venture capital investments are Germany, Spain and Italy. However, the new area of genuine venture capital investment seems to consist only of Germany and Spain, where the focus on the development of high-tech firms is 
attracting operators' interest. In Italy, on the other hand, there is a clear prevalence of expansion financing operations.

In countries such as France, Sweden and the Netherlands, investors showed a decided preference for replacement and buy-out operations during 2006.

One of the explanations lies in the high returns associated with buyout operations and later investment projects in general. The excessive focus on buy-out operations may have put the brakes on the development of the venture capital segment. It is, however, undeniable that the growth of the venture capital market has been affected by factors related to both the demand and supply of risk capital. In this area, various studies of the US market reveal that it is probably demand, rather than the availability of capital, that restricts the growth of the industry (Gompers and Lerner, 1998).

This same conclusion emerges from our earlier survey, which identifies a clear lag between fund-raising and investment. This discrepancy confirms the market shortage of investment opportunities that meet the risk/return profiles required by operators.

Paradoxically, this surplus capital might in itself be the cause of another problem. One of the most important challenges with which the sector has to deal is the crowding of the market due to the availability of huge amounts of money at low cost. Competition between funds is growing fast, and this is partly a healthy development, but price competition may become excessive due to the fact that all the capital is being offered to the same limited number of firms. An excess of supply can have an inflationary effect, making it more difficult to generate value after the acquisition.

Another factor which may restrict the industry's growth is the availability of high skill levels among operators. Bottazzi and Da Rin (2002) find that in Europe venture capital is not systematically associated with particularly dynamic companies, whether we look at sales growth, new employment or stock market performance. As Bottazzi and Da Rin underline, their study does not allow definitive conclusions to be drawn, but the supply of skilled human capital emerges as one of the potential problems. There is no doubt that the venture capitalist has to operate in an extremely complex context: a start-up relies on the talent and skills of its founder, who knows more about its technical aspects than anybody else. This makes it particularly difficult to assess performances and, as stated in chapter 5 , the investor is required to provide technical skills above and beyond financial expertise as such. 


\section{PROOF}

Size and Evolution of the Risk Capital Industry 109

Another problematic factor is the perception that the market, in the widest sense, has of these operators. Calling risk capital investors locusts may be unjustified, but the problem of their relations with the market and its stakeholders in general is a growing one. If private equity wishes to survive in the long term, it must establish an acceptable relationship with all stakeholders. Unlike alternative operators, such as hedge funds, private equity investors constitute an asset class whose results depend on their ability to create value for the firm in the broadest sense. 